La pena desde la axiología jurídica, a partir del itinerario jurídico de Jorge Zavala Baquerizo

\title{
La pena desde la axiología jurídica, a partir del itinerario jurídico de Jorge Zavala Baquerizo
}

The penalty from the legal axiology, from the juridical itinerary of Jorge Zavala Baquerizo

\section{A penalidade da axiologia jurídica, do itinerário jurídico de Jorge Zavala Baquerizo}

\author{
Lenin T. Arroyo-Baltán I \\ arroblente@hotmail.com \\ José J. Albert- Márquez II \\ albertmarquez@hotmail.com
}

Recibido: 14 de septiembre de 2017 * Corregido: 05 de octubre de 2017 * Aceptado: 22 de noviembre de 2017

I. Doctor en Jurisprudencia, Magister en Ciencias Penales y Criminológicas, Abogado de los Tribunales y Juzgados de la República del Ecuador, Licenciado en Ciencias Sociales y Políticas, Docente de la Facultad de Derecho de la Universidad Laica Eloy Alfaro de Manabí, Manta, Ecuador.

II. P.h.D., Secretario Académico la Facultad de Derecho y CC. EE. y Empresariales Responsable de Calidad, Profesor de Filosofía, Docente de la Universidad de Córdoba, Córdoba, España, 


\section{Resumen}

Este trabajo tuvo como objetivo realizar un análisis de la pena y de las teorías sobre los fines de la misma y de las improntas del itinerario jurídico del ilustre maestro Jorge Zavala Baquerizo sobre la teoría de la pena. La metodología utilizada fue de tipo descriptivo documental bajo un enfoque cualitativo. El corpus de la investigación estuvo constituido por la revisión bibliográfica y documental de los estamentos legales y teóricos de la pena jurídica ecuatoriana y de las improntas del itinerario jurídico del ilustre maestro Jorge Zavala Baquerizo sobre la teoría de la pena. Los resultados se fundamentaron en el origen, justificación y naturaleza de la pena, desde el paradigma del principio de legalidad reglado en el numeral 3 del artículo 76 de la Constitución de la República del Ecuador. Entre sus conclusiones, fue posible considerar que actualmente es necesario fortalecer y apoyar la investigación científica, el análisis o revisión objetiva de las teorías retributivas de la pena, bajo rigor académico, partiendo de las improntas de las tendencias neo-retribucionistas.

Palabras clave: justificación y fines de la pena; retribución; prevención; neo-retribución; Zavala.

\section{Abstract}

This work aimed to make an analysis of the penalty and theories about the purposes of the same and the imprints of the legal route of the illustrious master Jorge Zavala Baquerizo on the theory of the penalty. The methodology used was descriptive documentary under a qualitative approach. The corpus of the research was formed by the bibliographic and documentary review of theoretical and legal sectors of the Ecuadorian legal penalty and the imprints of the legal route of the illustrious master Jorge Zavala Baquerizo on the theory of the penalty. Results are based on the origin, rationale and nature of the penalty, from the paradigm of the principle of legality is regulated in paragraph 3 of article 76 of the Constitution of the Republic of Ecuador. Among its conclusions, it was possible to consider that it is now necessary to strengthen and support scientific research, analysis or review objective remuneration theories of punishment, under academic rigor, based on the imprints of the trends neo-retribucionistas.

Key words: justification and purposes of punishment; retribution; prevention; neo-retribution; Zavala. 


\section{Resumo}

O objetivo deste trabalho foi analisar a punição e as teorias sobre seus fins e as marcas do caminho jurídico do ilustre mestre Jorge Zavala Baquerizo sobre a teoria da punição. A metodologia utilizada foi o documentário descritivo com abordagem qualitativa. $\mathrm{O}$ corpus da pesquisa consistiu em uma revisão da literatura e documentar os níveis legais e teóricos da punição legal do Equador e as impressões legais itinerário Jorge Zavala Baquerizo professor ilustre sobre a teoria da punição. Os resultados foram baseados na origem, justificativa e natureza da sentença, a partir do paradigma do princípio da legalidade regulado no numeral 3 do artigo 76 da Constituição da República do Equador. Entre as suas conclusões, era possível considerar que é agora necessário reforçar e apoiar a investigação científica, análise e revisão objetiva das teorias retributivas de punição, de baixo rigor acadêmico, com base nas impressões de tendências neo-retributiva.

Palavras chave: justificação e fins de punição; retribuição prevenção; neo-retribuição; Zavala.

\section{Introducción}

Construir es una tarea humana. Es hacer con los elementos necesarios -siguiendo obviamente un método- la obra científica a perpetuidad o como nuevo paradigma. Sin embargo, son múltiples las funciones atribuidas al derecho penal, entre ellas: -la más comúnmente aceptada por la doctrina dominante- resulta ser la protección de los bienes jurídicos, independientemente, de constituirse en un instrumento normativo que sirve para garantizar la paz y la convivencia social al margen del injusto penal. El derecho penal es un conjunto de normas jurídicas, de acuerdo con el razonamiento de Welzel (1987) su misión consiste en desarrollar y explicar el contenido de estas reglas jurídicas en su conexión, es decir, sistemáticamente. Como ciencia sistemática establece la base para la administración de justicia igualitaria y justa, ya que solo la comprensión de las conexiones internas del derecho, liberan a su aplicación del ocaso y la arbitrariedad (Vidaurri, 2012). Así, para Vidaurri (1999), "el derecho penal es una de las expresiones del control social formal, perteneciente al ordenamiento jurídico público, reguladora del poder punitivo del Estado, que se encarga del estudio científico del delito, las penas y las medidas de seguridad”. (p. 297 y ss.)

El presente abordaje sobre el estudio de la teoría de la pena en el que obviamente, el punto de partida son todas aquellas respuestas que han sido proporcionadas, a través del curso de la historia, al 
La pena desde la axiología jurídica, a partir del itinerario jurídico de Jorge Zavala Baquerizo

dramático problema: ¿por qué se pena? En la indagación de la respuesta objetiva, se han enunciado varias teorías: absolutas o retributivas, preventivas, puras o mixtas y las tendencias actuales neoretributivas que, al mismo tiempo, han creado la necesidad (en especial, éstas últimas) de replantear los aspectos más inhumanos de la punición estatal. La pena, como legítima reacción contra la conducta delictuosa, se convierte así en el principal instrumento de represión estatal como reacción frente a la comisión u omisión del delito en el sentido de restricción de derechos al sujeto que adecua su conducta milimétricamente al presupuesto de hecho contenido en la norma penal. A través de la pena se busca mantener ciertos niveles de coexistencia humana. Importa entonces identificar cuatro aspectos en concreto que caracterizan a la pena como respuesta institucionalizada como consecuencia jurídica del delito: el origen, la justificación, la naturaleza y los fines que persigue.

En efecto, la retribución y la prevención son los dos elementos teóricos acerca del origen, naturaleza, justificación y los fines de la pena que, históricamente, se han mantenido en permanente conflicto. Frente al profuso ataque a la prevención general positiva y el aparente fracaso del ideal resocializador, últimamente se ha venido planteando la posibilidad de revisar las teorías absolutas o redistributivas de la pena, con la finalidad de establecer los mecanismos adecuados que posibiliten su aplicación con relación al progreso del neo-retribucionismo. (Durán, 2011).

En lo principal, el objeto de estudio de este trabajo es pasar una mirada a la teoría de la pena, a partir del itinerario del profesor Jorge Zavala Baquerizo, por su afán de buscar a través de la justicia, la igualdad y la transparencia para determinar una pena, es decir, en la actualidad se intenta combatir la idea distributiva de la prevención, de acuerdo con la cual la medida de la pena se puede incrementarse en función de los pronósticos que se puedan hacer sobre eventos y progresos en el futuro. (Feijoo, 2007)

Por ello, analizaremos en qué consiste la pena, así como las posibilidades de interpretarla: origen, justificación y naturaleza. La existencia de las teorías sobre los fines de las penas. Las medidas de seguridad, la doble vía del derecho penal, la justificación de dicha doble vía y establecer los presupuestos y duración de las medidas de seguridad. Así, como también, enfocaremos la suspensión condicional de la pena, ya que al ser la misma un instrumento a través del cual se restringen o se privan derechos del sujeto activo del hecho delictual, su naturaleza, al ser una suerte de castigo no puede ser desproporcionado, el mismo debe ser proporcional a la gravedad de la acción u omisión 
ejecutada. En definitiva, los fines que persigue la pena siempre serán diversos de acuerdo a la teoría de la pena con la que se aborde.

En definitiva, para explicar las diversas teorías sobre los fines de la pena, es necesario recordar que, parten desde los puntos de vista: retributivos o preventivos, puros o mixtos y neo-retributivos que se encargan de fundamentar de diverso modo y de explicar los presupuestos que condicionan el ejercicio del ius puniendi y la finalidad del Estado en su afán de perseguir con la pena. A nuestro juicio, en la actualidad se hace necesario retomar el análisis o revisión objetiva de las teorías retributivas de la pena bajo rigor académico, teniendo como punto de partida la revisión de las tendencias neoretribucionistas.

\section{Desarrollo}

\section{Concepto general de pena}

La expresión pena proviene del latín poena, que significa castigo, tormento físico, padecimiento, sufrimiento. Desde luego, la pena simboliza el mal que debe imponerse al culpable o responsable de la comisión de un delito. Es una figura previamente creada por el legislador, en forma escrita y estricta, al amparo del "principio de legalidad" (Bramont-Arias, 2000 y Villa, 1998), donde toda persona debe ser -en su caso- castigada si el hecho está previsto en la ley penal como delito con anterioridad a la comisión del mismo.

En síntesis, dicho principio, es la piedra angular en donde descansa de manera general todo el ordenamiento jurídico estatal y particularmente, del derecho penal, representado por el apotegma latino: nullum crime, nulla poena sine lege. En dicho sentido, la pena "es un castigo consistente en la privación de un bien jurídico por la autoridad legalmente determinada a quien, tras un debido proceso, aparece como responsable de una infracción del Derecho y a causa de dicha infracción". (Cobo del Rosal y Vives, 1990, p. 616)

\section{Origen, justificación y naturaleza de la pena}

Como modernamente sólo el Estado mantiene el poder monopólico para crear delitos y fijar sus penas o sanciones, se constituye en la única fuente de producción de derecho penal. Por lo tanto, la norma jurídica no es otra cosa que la voluntad del sujeto de la soberanía, es decir, que, en rigor, la única 
fuente de producción del derecho penal es el mismo Estado, aun cuando éste -como se pronuncia Grispigni (1948) - no reserva exclusivamente a sus propios órganos la función de la producción del derecho objetivo y la confiere también a otros sujetos (Muñoz Conde, 1977). Junto a estos imperativos de la naturaleza de la pena, para entender con mayor claridad esta cuestión, es necesario distinguir tres aspectos importantes de la pena, a saber: la justificación, el fundamento y el fin; en los próximos apartados se analizan brevemente las teorías que asumen el protagonismo de los tres aspectos señalados.

\section{Teorías sobre los fines de las penas}

La visión más importante de la discusión acerca de estas teorías consiste en que la pena se justifica por su necesidad como medio de represión necesario para conservar las condiciones de vida fundamentales para la convivencia social de las personas en una comunidad determinada. También se puede decir que, sin la pena, (o al menos sin la posibilidad de imponer una pena a los considerados culpables de un delito) dicha convivencia -en la actualidad- sería imposible. En este contexto, el principal medio con el que cuenta el Estado como mecanismo de reacción frente al delito es la pena. En otras palabras: se trata de la restricción de derechos del justiciable que a través de un debido proceso ha sido declarado culpable o responsable de la comisión u omisión de un injusto penal. En este ámbito de corte jurídico cabe también la medida de seguridad para atenuar circunstancias respecto de las cuales el uso de las penas no resulta meritorio.

Este enunciado pone claramente de manifiesto que desde la antigüedad se viene discutiendo acerca del fin y fundamento de la pena a través de tres diversas ideas teorizantes que en sus variadas composiciones permanecen aún en la discusión científica. En síntesis, esas diversas ideas teorizantes nos permiten establecer la función de la sanción penal, y a su vez, reconocen también, cuál es el fin o función del saber normativo penal. Así, pues, para continuar con esta discusión desde la doctrina y desde la legislación positiva penal, es necesario abordar la génesis de las diferentes tendencias: absolutas, relativas y mixtas o de la unión (más las correspondientes subdivisiones) que se encargan de fundamentar de diverso modo y de explicar los presupuestos que limitan el ejercicio del ius puniendi. 


\section{Teorías absolutas}

El estudio del delito implica un acercamiento directo a la reparación y la retribución, las cuales pueden identificarse con la justicia absoluta. La reparación, presume el restablecimiento de la situación anterior al delito; es decir, pretende borrar el hecho delictivo perpetrado, puesto que, parte sobre la base de un orden establecido impuesto por la divinidad; por lo tanto, el delito, constituye un acto de rebelión contra dicho orden. En otras palabras, dicho acto, es un pecado, y consecuentemente, la pena tiene un fin en sí misma. Lo cierto es que dicho fin, impide la rigurosidad de la venganza divina.

En la antigüedad, la formulación teórica de la reparación o retribución fue sustentada por Platón, y en la modernidad por el conde saboyano José de Maistre (1753-1821), llegándose a conceptuarla así: "la retribución, compensación del mal del delito por el mal de la pena, exige que el delincuente sea castigado por el solo hecho de haber delinquido, sin consideración a ninguna finalidad ulterior de la pena, que debe seguir al delito como la sombra al cuerpo". (Labatut, 1979, p. 52)

En ese sentido se piensa que la pena tiene también, un fin intrínseco en sí misma, como queda explicado. De esta manera, será preciso su análisis e investigación, por cuanto revela múltiples delitos, así como la tangible interacción con el delincuente. El origen histórico de las teorías absolutas de las penas se puede explicar, "como una reacción ideológica centrada en la revalorización del hombre como tal y en sí mismo y en preocupación por la dignidad del condenado- por parte de los primeros revolucionarios burgueses, frente a los abusos del Antiguo Régimen y en contra de las concepciones utilitaristas de la pena, muchas de ellas fundadas en el contrato social, propuestas por los penalistas de la Ilustración" (Durán, 2011, p. 125).

Con ironía se asevera que tanto La metafísica de las costumbres de Kant (1989) como La filosofía del derecho de Hegel (1968); citados por Hassemer y Muñoz Conde (1989, p. 151), convienen concebirse como productos de la discusión que estos filósofos mantenían contra la idea relativista de la pena que dominaba en su época, a la que justamente increpaba Hegel que "trataba al condenado como a un perro con un palo, en lugar de respetar su honor y su libertad". Y a la que Kant del mismo modo criticaba el hecho de que el condenado pudiera ser "utilizado como un simple medio de las intenciones de otro y mezclado con los objetos del derecho patrimonial”, tanto si la pena se imponía en su 
La pena desde la axiología jurídica, a partir del itinerario jurídico de Jorge Zavala Baquerizo

beneficio, como en el de otro. (Hassemer y Muñoz Conde, 1989, p. 151; citados por Durán, 2011, p. 125)

Kant y Hegel, máximos representantes del idealismo alemán parten de una deducción: la existencia de verdades o valores absolutos anteriores al hombre y a la mujer. Por consiguiente, estas teorías afirman que la pena no tiene más razón de ser que la precedente comisión de un delito. Pues, se trata de hacer con la pena justicia. Es decir, que sus fines son alcanzar la justicia o afirmar la vigencia del derecho, lo cual, desde luego, es la afirmación del derecho que ha sido negado por la comisión del delito. Por tanto, el derecho penal se legitimaría como instrumento eficaz para lograr la justicia a través de la retribución. Esto implica como consecuencia imponer un castigo a quien ha causado un mal. En resumen: dicha concepción retributiva de la pena presupone el concepto del libre albedrío, toda vez que, parte del hecho de que un hombre o una mujer puedan decidir en forma libre y voluntaria entre el bien y el mal. Por su parte, Kant, a través de sus importantes estudios, concluyó que la pena no es un medio sino un fin y, en tal sentido, como supuesta teoría absoluta, se opone a las teorías llamadas relativas. Es evidente que, este simplismo genera una confusión que finca en el hecho de que la pena es un fin en sí misma y debe entenderse en el ámbito de las penas en particular, pero no porque en general no le asigne a la punición una función: de lo contrario la teoría kantiana sería irracional o dogmática, como Zaffaroni, et al. (2000) sostienen:

Si la teoría de la pena de Kant se denomina absoluta porque es enteramente deductiva, sin admitir ningún dato empírico, el calificativo es válido, al igual que sí se sostiene que en cada caso particular se debe retribuir sin reparar a la conveniencia o inconveniencia casuística. Pero si se la denomina de esta forma porque se entiende que la propia acción punitiva no persigue ningún objetivo o finalidad, el calificativo es falso, porque para Kant la ley penal no es menos defensista social que para los restantes contractualistas. (p. 266)

Es además explicable - de acuerdo al razonamiento de Zaffaroni, et al. (2000)- que no se justifica la pretensión de volver hoy al retribucionismo, como forma de salir del atolladero, ante el fracaso de las otras teorías de la pena, pues, no es más que seguir girando dentro del mismo atolladero, lo cual compartimos plenamente, y con beneplácito nos afiliamos al nuevo paradigma etiológico del estudio de la ciencia del derecho penal, propuesta por los mencionados autores. 
Se considera erróneamente, que la teoría absoluta de la pena, como toda obra humana tiene demarcado sus límites. Empero, ella constituye el avance o progreso del estudio del derecho penal, frente a las ideas primitivas de la venganza. Sobre todo, en cuanto a la responsabilidad penal instituida en el libre albedrío, reconociéndose la proporcionalidad entre el delito y la pena. A pesar del significativo avance, dicha teoría de la reparación o retribución es falsa y peligrosa.

Se acepta en este juicio el criterio de Labatut (1979): esa teoría sería "falsa, porque la justicia absoluta es superior a las posibilidades humanas; peligrosa, porque conduce a la confusión de la ley penal con la ley moral y religiosa" (p. 53). De ahí que exprese el referido autor, que resulta preciso convenir que el miedo a la venganza divina se encuentra muy radicado en la conciencia popular.

En efecto, se puede señalar que, para esta tendencia dogmática, la pena carece de finalidades, puesto que se resuelve en sí misma. Es decir, que la pena es ella misma, una finalidad, pero carece de finalidades. Y, por consiguiente, es finalidad en tanto es consecuencia de la alteración del orden establecido (Zavala, 1986a). En resumen: hacer justicia es el soporte filosófico del castigo.

Las teorías absolutas en esencia deducen que la pena es una retribución, puesto que de lo que se trata es de retribuir con una pena a quien ha cometido un delito. De acuerdo con esta tendencia del pensamiento, la pena no sirve básicamente a fines sociales sino a la idea de justicia. Dicho de otra manera, la pena ha de existir para que reine la justicia entre los hombres y mujeres del planeta.

Los más insignes exponentes de esta corriente retribucionista, fueron los filósofos alemanes Kant y Hegel, como ya se había anotado. No hay que olvidar que Kant, fue uno de los grandes filósofos de la Ilustración, y sumamente cristiano, al punto que su religiosidad fue importante para toda su filosofía, así como lo fueron sus conocimientos sobre el pensamiento racionalista de Descartes y Spinoza, y de empiristas como Locke, Berkeley y Hume. Para Kant tanto la percepción como la razón jugaban un papel importante al momento de percibir el mundo. Para él la ley causal rige siempre y de manera absoluta simplemente porque la razón del hombre capta lo que sucede como una relación causa-efecto. Kant, al estar de acuerdo con Hume en que no podemos saber nada seguro sobre cómo es el mundo en sí, estima que sólo podemos saber cómo es para mí; separa la "cosa en sí" de la "cosa para mí”. De lo cual instituyó dos cosas que contribuyeron al conocimiento del mundo: la percepción y la razón. 
Para Kant la religión no era otra cosa que una cuestión de fe, de tal manera que resultaba ineludible para la moral de los hombres y mujeres suponer que tienen unas almas inmortales, que existe un [dios], y que los hombres y las mujeres tienen libre albedrío, es decir, la potestad para decidir en forma libre y voluntaria entre el bien y el mal y que pueden racionalizar los valores, como hemos señalado.

\section{Teorías absolutas de la retribución}

Sin llegar a deslegitimar su posición absolutista, estas tendencias, se someten de manera colectiva a las formulaciones técnicas: punitur, quia peccatum est (teoría absoluta); y, punitur, ne peccetur (teoría relativa). Como hemos dejado indicado, en la actualidad, de estas tendencias se puede observar claramente, que sólo se castiga para mantener el orden social, es decir, que su orientación está dada, en su interés por la estabilidad de la norma jurídico-penal.

Por lo tanto, lo legítimo para estas tendencias es que la discusión gira en torno a si la pena ha de establecerse en virtud de dicha función o si tiene un contenido independiente de esta función, de tal manera que la pena debe garantizar la seguridad de las expectativas posibles y no posibles de las relaciones sociales, posibilitándose desde luego, la existencia misma de la sociedad. Sin duda habría, y hay, dos marcadas discrepancias de detalle a la hora de señalar las expectativas posibles y no posibles de dichas relaciones concretas, a saber: la primera, alude a que lo que debe garantizarse no es el Estado positivo de la sociedad, sino la justicia; por el contrario, la segunda, afirma que la garantía no debe confrontarse de manera que se manipule al autor del injusto penal como medio para fomentar el bien de los demás.

De estos puntos de vista, aunque rechazamos la retribución de la pena por la existencia de límites implícitos en sentido estricto y jurídico, por el fondo de dichas afirmaciones antagónicas, nos resulta dificultoso apreciar su fortaleza, ya que en la doctrina penal no se defiende el fomento de la justicia como fin autónomo, e inclusive históricamente sólo se ha defendido en asuntos totalmente aislados. Por ejemplo, en la retribución como pago del mal con el mal se trata de la racionalización de la venganza. Sin embargo, no se trata de una especie de legalización absoluta de la pena. Por el contrario, se trata precisamente, de una limitación absoluta de una pena definida relativamente o del respaldo concerniente de una justificación absoluta que se la puede apreciar limitadamente. 
Si se considera dicho razonamiento, para recordar que el umbral retributivo más conocido, es el talión, lo que equivalía a la retribución de un mal con otro igual. Consecuentemente, nos encontramos, entonces, frente a una limitación de la pena. Para examinar mejor estos aspectos, se analiza a continuación brevemente las tendencias retributivas.

\section{Teoría teológica de la retribución de la pena}

La posible existencia de esta tendencia, derivaría de la hipótesis que el Estado es obra de Dios, por consiguiente, el delito es ante todo una violación de los preceptos divinos y en subsidio la pena debe seguir al delito, por cuanto, ella también, deriva de la voluntad divina que requiere de la reparación a través de la angustia o sufrimiento del penado, a quien está impedido solicitar compasión, pues de aceptarla significaría la validación de la inestabilidad social inducida por la comisión del delito (Zavala, 1986a). Sin embargo, atendiendo a la ubicación temporal, se puede colegir que la sustentación de esta teoría teológica de la retribución de la pena [o retribución divina] está precisamente- en el denominado Antiguo Régimen. Es decir, abarca los efectos de la historia criminológica desde los albores de la humanidad en monarquías teocráticas y castas sacerdotales gobernantes en el Antiguo Egipto y Mesopotamia Asiática (Marí, 1983). Las penas en el Antiguo Régimen Español datan desde el siglo XII al XVIII.

De esta manera, la pena lleva consigo un fin en sí misma. Siempre y casi siempre, con su imposición se repara el daño causado a la ley divina a través de los mandatos del Estado, el que constituye, sin duda, para esta tendencia, una herencia recibida de Dios por los hombres y mujeres. Pero a nuestro entender la situación se complica, puesto que, por el mismo hecho de violar la ley divina, viene consigo la venganza (de dios o de los dioses, comúnmente conocida como la furia de dios o de los dioses). Empero, para la imposición de la sanción de la divinidad, se interponen otras causas, sean éstas humanas o naturales, lo que nos hace pensar, que ni el Estado, ni el derecho, ni la pena tienen origen divino, sino que son obras humanas.

En ese sentido es posible sugerir que, como en ninguna obra humana hay perfección, en el Estado, el derecho y la pena no son perfectos, pero son perfectibles en la medida que se consolide el verdadero Estado constitucional de derechos y justicia, y se mantenga una Constitución democrática, preferentemente abierta a todas las ideologías antagónicas. 


\section{Teoría teológica de la retribución moral de la pena}

Para Kant, el contenido de la pena es el talión: "si ha matado, debe morir". Es decir, para él la función de la pena consiste en la realización de la justicia, al sostener que la pena sólo puede imponerse contra el autor del injusto penal, simplemente porque ha delinquido. De tal manera que, si se persigue la prevención general o especial, se trata a la persona como un medio para los propósitos de otro y se las confunde con los objetos de los derechos reales.

En efecto, Kant; citado por Zavala (1986a) sentenció que la justicia penal es un imperativo categórico, por lo tanto, si desaparece la justicia ya no tendrá valor alguno que vivan los hombres sobre la tierra (Welzel, 1956, 1965 y Zambrano, 1998). Kant; citado por Zavala (1986a) afirma que la norma jurídico-penal constituye un imperativo categórico, pues de ella se exige una conducta determinada a los miembros de la sociedad, los cuales quedan obligados a cumplir con dicho mandato, sea porque moralmente se supone que así deben hacerlo, sea porque legalmente deben hacerlo.

Si asumimos la hipótesis de Kant en el sentido que la única solución acerca del carácter categórico del derecho penal, es que la sociedad se disuelva por mutuo acuerdo, según el cual solamente cabría "ejecutarse antes al último asesino que se encuentre en prisión”; de ser así, entonces, la misma sociedad resultaría "cómplice en la vulneración pública de la justicia", por tanto, tiene su valor propio, pero no creemos que la sociedad deba disolverse por un simple contrato social, ni menos pretender la ejecución hasta el último asesino que se encuentre en prisión. Así pues, hacerlo equivale, sin duda, a la desnaturalización o descomposición del ordenamiento jurídico, por cuanto, la pena resultaría ilegítima, es decir, sin valor por la ausencia del ius puniendi. No hay que olvidar que Kant desplazó el conflicto de la pena desde el punto de vista de lo que se propone el juzgador al punto de vista singular de la pena misma, lo cual resulta ser una justa retribución por el mal causado por el delincuente.

Desde luego, el atributo de la teoría kantiana radica en considerar que, el "pecador" altera el orden preestablecido provocando un desequilibrio dentro del mismo, llegando a la conclusión que el castigo es consecuencia necesaria y fatal del pecado. Sin embargo, la norma moral es un imperativo y no un mero consejo. Así sucede con la norma jurídica, que intrínsecamente trama la imposición del castigo 
al "pecador"; es decir, que el delincuente es castigado simple y llanamente por haber delinquido, sin que el Estado tenga la potestad de buscar los fines determinados de la pena.

De esa manera, para Kant el castigo sería el motivo por el cual llámase a algo un delito, y la justicia debería consistir en esto. Por lo tanto, el hecho de inhibirse de todo castigo e impedir aún aquellos naturales, daría como resultado que en la ejecución de la acción no habría nada malo. Por el contrario, dichos males seguirían, y por ello, muy bien se los puede identificar como una mala acción. Zavala (1986a) considera que la pena es consecuencia del delito, con lo que estamos plenamente de acuerdo, puesto que, la pena es una consecuencia del combate contra el delito. Pues, siguiendo al insigne maestro:

(...) lo que nos interesa es la retribución tal cual es hoy entendida, esto es, como aquella correspondencia justa entre la pena y la medida de culpabilidad, la que, (...), jamás podrá ser alcanzada. Y tal imposibilidad, entonces, deja sin base a la retribución cual es hoy concebida, aunque se mantenga el criterio primitivo del castigo por el castigo mismo. (p.168)

Sobre la base de lo expuesto, no debemos pasar por alto que, para las teorías absolutas retributivas más recientes:

(...) la pena se justifica por su necesidad como medio de represión indispensable para mantener las condiciones de vida fundamentales (...) ( sin la cual) la convivencia humana en la sociedad sería imposible. Su justificación no es, por consiguiente, una cuestión religiosa ni filosófica, sino una amarga necesidad. (Muñoz Conde y García Arán, 1996, pp. 47-48)

Además, la pena se halla sometida a la reserva de su necesidad social. Es decir, que la pena no puede sobrepasar el límite absolutamente mensurable. Por lo tanto, no debe imponérsela con carácter absoluto, ni tampoco puede sobrepasarse en absoluto. En resumen: no somos partidarios de la retribución moral de la pena, dentro del contexto de la fórmula "castigo por castigo". Pues, de ser así concebida, la sociedad resultaría retrograda en el sentido de convertirse en vengadora pública, y cometería otro delito mucho más grave y repudiable en nombre de la justicia. 


\section{Teoría jurídica de la retribución de la pena}

En cierto sentido, y desde un punto de vista jurídico, ya los dos más grandes filósofos europeos de la época, Kant y Hegel, uno antes y el otro después de la Revolución Francesa, sostenían una rigurosa teoría retributiva de la pena y llegaban inclusive a la conclusión de que la pena de muerte es inclusive un deber. Kant, partiendo del concepto retributivo de la pena, según el cual la función de ella no es la de prevenir los delitos, sino, estrictamente, hacer justicia. Es decir, hacer que haya una perfecta correspondencia entre el delito y la sanción o castigo. Hegel va mucho más allá, tras haber refutado el argumento contractualista de Beccaria, al negar que el Estado pueda nacer de un contrato, y al sostener que el delincuente no sólo ha de ser castigado con una pena que corresponda al delito que ha cometido, sino que tiene derecho a ser castigado con la muerte porque sólo el castigo lo rescata y sólo castigándolo se lo reconoce como un ser racional. No obstante, Hegel guarda lealtad a la obra de Beccaria al reconocer que la misma tuvo como efecto la reducción del número de las condenas a muerte. (Bobbio, 2001)

\section{Para Hegel (1986a):}

La coerción tiene la real representación de que ella se destruye a sí misma ya en su propio concepto en que la coerción es cancelada a través de coerción; por esto, ella no solo es conforme a derecho condicionadamente, sino que es necesaria -a saber-, como segunda coerción, que es cancelación de una primera coerción. (p.93)

Como se sabe, la punición es realización de validez jurídica. Es decir, la contradicción del derecho. El injusto es la negación del derecho, y el injusto criminal es la negación del derecho en cuanto que éste se manifiesta como realización de una voluntad particular cuyo valor declarativo, desde el punto de vista del derecho, se agota en la negación del derecho. Lo que desde luego se puede verificar en que el delito, como expresión de una voluntad que lesiona el derecho en cuanto derecho, es un juicio negativo, a decir de Hegel (1986a):

Si bien la lesión del derecho en cuanto derecho tiene ya una existencia positiva, exterior, ella es en sí misma nula. La manifestación de su nulidad es la negación de aquella lesión, que de igual modo tiene existencia la realidad del derecho, como su necesidad que media consigo misma a través de la cancelación de su propia lesión. (p. 97) 
La pena desde la axiología jurídica, a partir del itinerario jurídico de Jorge Zavala Baquerizo

Lo que interesa es subrayar que para Hegel (1986a) el delito es la "negación del derecho", y la pena sería como la "negación de la negación". Dogmatiza así por su parte que la pena de acuerdo con el ordenamiento jurídico representa la voluntad general y niega con la misma la voluntad especial del delincuente expresado en la lesión jurídica que -por supuesto-queda anulada por la superioridad moral de la comunidad. Descalifica, por tanto, la persecución de fines distintos a la mera retribución del derecho lesionado a través de la pena.

Así, "definir el derecho abstracto o estricto, desde el principio, como un derecho que se puede imponer coercitivamente, significa conceptualizarlo en atención a una consecuencia a la que se llega recién por el desvío del injusto" (Hegel, 1986a, p. 94). La realización del derecho, sin embargo, se produce en la autoconciencia de la sociedad desde el punto de vista político que, reconociendo la necesidad de su propia determinación como libertad (Hegel, 1986a), se torna "eticidad”, considerada como categoría del "espíritu objetivo". Esta categoría se halla anticipada ya en el aparecimiento de la autoconciencia individual como categoría del "espíritu subjetivo": se trata de "el yo que es nosotros, y el nosotros que es el yo". (Hegel, 1986b, p. 145)

Para Hegel (1986a) el carácter retributivo de la pena se justifica por la necesidad de restablecer la vigencia de la voluntad general, que resulta negada por la voluntad del delincuente. Si la voluntad general es negada por la voluntad del delincuente, habrá que negar la voluntad del delincuente a través del castigo penal para que surja de nuevo la afirmación de la voluntad general. Por ello, podría sostenerse que el fin de la pena, entendido como el restablecimiento de la autoridad del derecho mediante la retribución del hecho culpable, es necesariamente alcanzado con la ejecución de la pena, de manera que no puede haber fin de la pena alguno que trascienda su ejecución (Binding, [n.37], pp. 234-235). A esta teoría de la retribución jurídica, hay que atender, como bien lo concibe Hegel (1986a); citado por Maurach (1962), y a su vez por Zavala (1986a) que el delito es "la violación con que el ser libre lesiona la existencia de la libertad, en su significado concreto, es decir, lesiona el derecho en cuanto derecho" (p. 144). Así pues, de dicha concepción del delito, Hegel (1986a y1986b); citado por Maurach (1962), y a su vez por Zavala (1986a) opina sobre la pena diciendo que es "la lesión de la voluntad del delincuente, la lesión de la lesión del derecho, la anulación del delito y la reintegración del derecho". (p. 144) 
Sobre dicho razonamiento, y emulando al insigne maestro ecuatoriano, el delincuente apuesta su libertad sobre la libertad de los demás, la cual rechaza. Como se puede observar -de acuerdo con Zavala (1986a)- el derecho es:

La tesis de la cual tiene que partirse necesariamente para poder comprender la naturaleza de la pena. El delito -lesión del derecho- es una negación de éste, por lo que se manifiesta como antítesis, siendo la pena -negación de la negación del derecho- la síntesis que permite la reintegración del derecho. La pena, pues, es necesaria por la sola razón de ser efecto del delito. (p. 144)

De todos modos, el derecho no podría restituirse, ni podría ser respetada la libertad de manera corriente si no surge la pena para anular el delito y asegurar la libertad. En resumen: la pena conlleva un fin en sí misma, como hemos dejado explicado.

Se cree, y -seguramente- se discrepa superficialmente con el insigne maestro ecuatoriano, en el sentido de que, si es verdad, que la pena anula el delito, empero, la pena no anula la angustia ni el sufrimiento de la víctima que deja el delito, lo que en la práctica diaria genera reacción, y esta reacción se convierte en venganza privada. Sin embargo, todo cuanto se corrobora así, y con la opinión de Cuello Calón (1960), citado por Zavala (1986a) es que se puede concebir que "la pena es la justa retribución del mal del delito proporcionada a la culpabilidad del reo, ésta es su esencia íntima" (p. 146). Es decir, que la sociedad exige el castigo del delincuente por haber causado el mal y su actuar violento contra el ordenamiento jurídico previamente establecido, lo que compartimos, pero lo que no podemos aceptar es que la sociedad en su afán de venganza, se olvide del sufrimiento o angustia de la víctima.

Es cierto que se ha pretendido encontrar un fundamento de la pena en la justa retribución del mal causado por la comisión del delito, en proporción con la culpabilidad del sujeto activo. Pero en realidad, se piensa en el moderno significado de la retribución. De manera que, este fundamento de la pena, no debe ser necesariamente el castigo, dolor o aflicción para el agente, sino la verdadera solución del conflicto que genera el delito, del cual no se puede excluir a la víctima. Es de notar, que lo principal es intentar volver, reforzar o construir un Estado social y democrático de derechos, contener la venganza, tanto privada como pública y no caer en la quimera de quienes piensan irresistiblemente 
que todo puede ser resuelto por el derecho penal, a través de la aplicación de una pena como consecuencia del delito.

Al respecto, Zaffaroni et al (2000) se refiere especialmente al significado moderno de la retribución como fundamento de la pena, lo que nos permite llegar a la simple conclusión de que el poder punitivo puede resolver muy pocas cosas, y es legítimo, en nuestra opinión, plantearse si puede resolver alguna cosa. Tal vez pueda brindar alguna tranquilidad a través de la suspensión de algún conflicto determinado, pero nada más.

\section{Tendencias reparadoras o expiatorias}

Respecto a estas tendencias, la literatura jurídico-penal ecuatoriana, es el propio Zavala (1986a) quien parte del hecho de que la pena es expiación y, por lo tanto:

El delito surge de la voluntad del hombre, la cual se encuentra viciada de la inmoralidad. De allí es que aquel que actuó con voluntad viciada por la inmoralidad debe ser aprehendido por la sociedad con el fin de purificarlo, de sanearle la voluntad, y esto solo se puede hacer a través de la expiación, a través del dolor que debe sufrir el condenado mientras devenga la pena. -Al mismo tiempo Zavala argumenta que-: (...) mientras no se imponga la pena no puede restaurarse el orden social, siendo por tanto de estricta necesidad, de una total fatalidad que al delito le siga la pena. (p. 141)

Precisamente con esto se confirma la función expiatoria de la pena. Es decir, que el delincuente tiene que sufrir la pena impuesta por los tribunales, obviamente establecida con anterioridad al acto delictivo. Desde luego, al examinar el asunto, la expiación como comprensión por parte del autor del injusto penal ejecutado, así como la necesidad de la pena, previenen ambas la consecuencia de una reconciliación con la sociedad, pues, en la actualidad no se propugna como función principal de la pena. Ello resultaría dudoso si el autor del injusto penal, desde luego, es capaz de responder por el hecho delictuoso, en torno al arrepentimiento, de esa manera, se piensa que la pena se adecue a la expiación, sin que se pretenda, por supuesto que la misma sea forzosa. Conviene dejar aclarado, antes de concluir el estudio de estas tendencias, que no se trata de un conflicto de la teoría de la pena. Por el contrario, en el momento en que entra en recreación la idea de que la expiación pueda contribuir a la legitimación de la pena como efecto secundario, nos nace la idea de que también es un efecto secundario la medida de seguridad del autor mientras dura el cumplimiento de la pena. 
Como corolario, se debe considerar que dentro de esta misma concepción absolutista reparadora ha surgido una posición de limitar los excesos a esta tendencia. Pues, considera que el delito impune siembra en la conciencia social una inseguridad absoluta, lo que, sin duda, significa un agravio a las normas jurídicas que intentan proteger los bienes esenciales del hombre y la mujer dentro de los predios de la sociedad. Resumiendo, en este fundamento de limitar los excesos en la expiación de la pena, puede decirse, -como sabiamente afirma Zavala (1986a)-, que "esta inseguridad y desconfianza sociales son el principal efecto del delito y, por tanto, es necesario que la pena siga al delito porque de esa manera se restablece la confianza en la sociedad, en el hombre, en el ordenamiento jurídico" (p. 144). La inseguridad sólo representa un papel secundario, que sirve para excluir la responsabilidad de los delincuentes vinculados al poder. De esta concepción, podemos formular esta conclusión: la promesa al autor del injusto penal de que éste puede reconciliarse con la sociedad, mediante la aceptación de la pena, resulta utópica puesto que la sociedad estigmatiza a todos aquellos que cometen una infracción; estigmatización que se traslada hasta la familia del delincuente, es decir, una característica de la venganza privada.

\section{Teorías relativas sobre la pena}

Se sabe que, dentro del grupo de las teorías relativas de la pena, al igual que en las absolutas, existen varias diferencias, por tanto, bien pueden clasificarse en tres grupos, a saber: las del pacto o contrato social, llamadas también, contractualistas; las utilitarias y las de la defensa social. De lo que antecede se deduce que, al examinar cada una de ellas, con la finalidad de entender los fundamentos del derecho penal y de la pena, según las variantes relativas, se presentan las siguientes teorías:

\section{Teoría del pacto social o contrato social}

Una de las variantes de las teorías relativas es la teoría del pacto social o mejor conocida como contrato social. Al respecto, Labatut (1979) relata que:

La idea del contrato o pacto social como fundamento de la función punitiva, que sirvió de base a la reforma penal humanitaria iniciada en el siglo XVIII, descansa en una utopía: que en una época remota, no precisada, los hombres vivían en Estado de naturaleza, dueños de la plenitud de sus derechos y ajenos a toda autoridad, gobierno o ley; y que posteriormente pasaron del Estado de 
naturaleza al Estado de sociedad, mediante un pacto de sumisión al poder elegido, en cuyas manos confiaron sus derechos.(p. 63)

Sobre el modelo de explicación no es consensual, puesto que, sobre el origen del derecho de castigar, existen distintos criterios. Unos consideran que es el derecho de defensa que posee el hombre y la mujer en su Estado de naturaleza y que habrían entregado al poder social. En cambio, otros reflexionan en el sentido que tanto el hombre y la mujer en su Estado de naturaleza conservan el derecho de castigar y que es éste el derecho que habrían transferido a la sociedad definitivamente.

En otra dirección, hay quienes piensan que, comprendiendo los hombres y las mujeres que no podían vivir sin leyes, habrían reconocido a la autoridad la facultad para perseguirlos y castigarlos, en la hipótesis de que se violaran las leyes de la sociedad, creadas mediante el pacto social. La teoría del contrato o pacto social se atribuye a Juan Jacobo Rousseau. Sin embargo, fue desarrollada y defendida por filósofos y juristas, como: Hugo Grocio, Thomas Hobbes, Baruch Spinoza, John Locke y Johann Gottlieb Fichte. Por su parte, Labatut (1979) argumenta que esta teoría es falsa:

Porque ni histórica ni sociológicamente es posible admitir que la sociedad se haya constituido por un acuerdo voluntario de sus miembros. La sociedad es un fenómeno natural que se impone al hombre, el cual, por las limitaciones de su propia naturaleza, que lo hacen incapaz de bastarse a sí mismo, es esencialmente sociable. Tanto sus instintos como sus necesidades lo conducen a ello. (p. 53)

Si bien es cierto que, no se comparte en su totalidad dicha ponencia, es posible asegurar que, la sociedad es captada como una estructura bien constituida, persistente y sólida, apoyada en el consenso acerca de los valores dominantes. Por otra parte, Labatut (1979) asegura que:

Son falsos también los orígenes que esta teoría atribuye al derecho de castigar, que no puede confundirse con el derecho de defensa; que supone autoridad y que, por tanto, no puede ejercitarse por un individuo en contra de otro; y que no puede tampoco haber sido cedido por los hombres al poder social, ya que, en el supuesto de que eso fuera efectivo, la autoridad no podría aplicar a sus subordinados otras sanciones que las correspondientes a los derechos cedidos, y los derechos fundamentales, como la vida y la libertad, son, por su esencia, irrenunciables.(p. 53) 
Efectivamente, los derechos fundamentales son irrenunciables, sin embargo, la renuncia de una parte de la libertad natural de los hombres y mujeres, de ninguna manera, significa que, la autoridad arbitrariamente atente contra sus súbditos, conminándoles el resto de su libertad natural. En resumen: el contrato o pacto social, "es una doctrina teleológica, porque afirma que la pena tiene como finalidad mantener el pacto social, asegurando con ello la pacífica convivencia de los seres humanos" (Labatut, 1979, p. 53). Pues, no hay que olvidar que el hombre y la mujer nacen libres, y es la misma sociedad que los conmina a delinquir y como si ello, fuera poco, son etiquetados por las mismas agencias de poder.

\section{Teoría utilitaria}

Bentham (1838) argumentó que, lo que justifica la pena es su utilidad, o mejor todavía, su necesidad. La pena es necesaria porque es el arma de que se vale el Estado para combatir la criminalidad; y para que el castigo sea justo, es condición necesaria y suficiente que el fin perseguido sea útil. Si la sociedad emplea la reacción penal contrariando los intereses colectivos, el castigo será injusto; pero si la emplea para proteger el derecho contra las ilícitas agresiones de los delincuentes, entonces el castigo es justo.

Con respecto a dicha argumentación, Labatut (1979) concluye que la misma "es maquiavélica, porque equivale a afirmar que el fin justifica los medios" (p. 154). Sin embargo, lo preciso es no olvidar que el utilitarismo subordina lo justo a lo útil, de acuerdo con la escala de valores que preconiza su filosofía. Sea como fuere, es un hecho que muchas penas han sido eliminadas, por ejemplo, las infamantes y las corporales, porque han sido estimadas injustas, sin consideración a sí son o no útiles. Entre las razones indicadas, el mismo autor asegura que "la teoría utilitaria conduce a la intimidación, y esto explica la relativa severidad del Código penal francés de 1810, cuyos redactores se inspiraron en ella". (Labatut, 1979, p. 154)

En este sentido, fu posible comprobar que la severidad del código penal ecuatoriano de 1872, con razón a su referida conexión con aquélla hipótesis que, obviamente, recibió el influjo del Código penal belga de 1867, el cual, a su vez, tuvo como base al referido código francés de 1810. Así, por ejemplo, se reprimía "la tentativa para abolir o variar en el Ecuador la religión católica apostólica y romana (...) con pena de muerte, si el culpable se hallara constituido en autoridad pública y cometiera la infracción abusando de ella”. (Código penal de 1872, art. 161) 


\section{Teoría de la defensa social}

Sintetizando, el objetivo de esta teoría es la defensa de la sociedad contra los delincuentes, como fundamento del derecho de penar, principio sustentado por la escuela positiva y por las tendencias penales modernas; empero, no fue ajena al pensamiento de la escuela clásica. Sin embargo, la moderna concepción de la defensa social tiene caracteres propios que la distinguen. Por ello, rechaza los principios del libre albedrío y de la responsabilidad moral como fundamento de la responsabilidad criminal; $y$, además, procura obtener un máximo de seguridad social con un mínimo de sufrimiento impuesto al delincuente, conforme a los fines que se asignan a la pena. (Labatut, 1979)

Bajo estos presupuestos, el tema de la pena no tiene únicamente carácter retributivo, si no que se interesa también de la protección de la sociedad, la misma, debe ser ejemplar y retributiva. Es decir, tiene el propósito de mejoramiento y aun de reducción del delincuente. De esta manera la justicia penal debe tener siempre presente la persona humana independientemente de las simples exigencias de la técnica procesal, con el fin de que el tratamiento penal sea siempre humano. Por lo tanto, es conveniente, entonces, construir el verdadero Estado de derecho constitucional abierto que brinde una base adecuada para el tratamiento humano de la pena.

Estos grupos de teorías se subdivide en contractualitas y positivistas. Los contractualitas como Locke, Hobbes, Montesquieu y Rousseau, consideraron que los hombres y mujeres, en función utilitaria habían cedido parte de sus derechos naturales a sociedad política -como la libertad- a fin de que el grupo social, a su vez, defienda los bienes y otros derechos de los individuos. En cambio, para los positivistas, el hombre y la mujer fueron el punto de partida para sus investigaciones penales, relacionándolos con el medio en que vivían y con la influencia que recibieron y que recibirían en el momento de la comisión de un injusto penal denominado delito por la ley penal (Zavala, 1986a). Si estos han sido los objetivos de estos grupos, la verdad es justificar mediante las explicaciones racionales, la imposición de un castigo, y sobre todo la utilidad de la pena. Más si esta hubiera sido la intención de sus exponentes, es evidente, entonces, que dichas concepciones son en el fondo parte activa contingente de formulación de las teorías relacionadas con los fundamentos del derecho penal y obviamente de la pena. 


\section{Teorías mixtas o de la unión}

La sociedad es captada como múltiple y plural, donde coinciden grupos con diferencias marcadas, y por lo tanto valores, metas e intereses diversos y aun contradictorios. Dicho mecanismo, independientemente de las teorías antes analizadas que constituyen la fundamentación del derecho penal, muy bien pueden resolver los conflictos que genera el delito. Sin embargo, existe un sistema ecléctico o mixto, que combina la doctrina utilitaria de Bentham (1838) con la del también filósofo alemán Kant (1797) sobre la retribución absoluta de la pena. Es probable que la elaboración de una fórmula mixta, llamada también por la doctrina "teoría de la unión" basada en la combinación de las teorías absolutas y relativas de la pena, resulte una de las cuestiones que mayores dificultades ofrece para la recepción de aquellas teorías en las que se fundamenta el derecho penal.

Por las consecuencias que se conectan a cada una de estas tendencias -como dice Bacigalupo (1984)es importante señalar que las teorías de la pena sólo son tales, en la medida en que la expresión se tome en sentido amplio. Pues, en realidad, no se trata de teorías sino de principios, cuya función es fundamentar el derecho penal. Por tanto, las teorías de la pena no responden a la pregunta ¿qué es la pena?, dado que el "ser" de la pena depende de la naturaleza que se le atribuya, sino a otra pregunta: ¿bajo qué condiciones es legítima la aplicación de una pena? Por cierto, las teorías mixtas o de la unión son las más acogidas en la actualidad por la doctrina jurídico-penal. Precisamente dentro de la diversidad de opiniones sobre los fundamentos de la pena, Rossi (1839) desarrolló particularmente el sistema mixto, y ha sido también uno de los autores más influyentes, puesto que, con su sabiduría inspiró la reforma del Código penal francés de 1832, y a través de la vigencia del Código belga de 1870 transmutó a la legislación penal ecuatoriana. En definitiva, de acuerdo con este sistema, llegamos a un punto en el que -siguiendo a Zaffaroni, et al. (2000)- se puede afirmar que:

La ley debe castigar en cuanto ello es necesario para el mantenimiento del orden social; pero debe hacerlo dentro de los límites de la justicia. El derecho de castigar, por consiguiente, encuentra su principio en la utilidad y su medida en la justicia. "No más de lo que es necesario ni más de lo que es justo". Esta fórmula puede ser considerada como la divisa del sistema. En su aplicación práctica, la pena impuesta al culpable debe graduarse atendiendo a su responsabilidad moral y a la gravedad objetiva del delito cometido (p. 265) 
En el sistema ecléctico o mixto, se encuentran influencias de la escuela clásica, en cuanto a la retribución de la pena, puesto que la misma sólo puede aplicarse a los individuos moralmente responsables. Por su parte, la responsabilidad es de carácter moral, consecuencia del libre albedrío. Todo ello, en combinación con la tesis kantiana sintetiza la reparación o redistribución de la justicia absoluta como condicionante de la razón humana, desde el punto de vista teórico y práctico. Estas tendencias, tratan de conjugar tanto la posición absoluta como la relativa, partiendo de la base que dentro de la sociedad existe un orden preestablecido por [dios] o por cualquier otro origen superior. Sin embargo, todo hombre y toda mujer, están obligados a respetar dicho orden. Pues, sólo así podrán gozar del respaldo que les brinda la sociedad; pero si ese orden es violado, entonces estarán obligados a expiar su falta a través de la pena. Entre sus defensores más destacados encontramos a Pessina, Pacheco, Carrara, Cuello, Fontán, Soler, Jiménez de Asúa, Núñez \& Carnelutti. (Zavala, 1986a)

\section{Las tendencias neo-retribucionistas de la pena}

Schünemann (2008), citado por Durán (2011) es quien, estableció las principales observaciones críticas o defectos lógicos que a su juicio se pueden aplicar directamente a la tendencia neoretribucionista del fin de la pena postulada por Jakobs basada en Kant.

Ciertamente, la primera crítica guarda relación con la idea de que el restablecimiento del derecho por medio de la retribución solo presupone la lesión de una norma jurídica como tal, pues con ello no se posibilita una limitación al derecho penal. Así, la opinión de Jakobs; citado por Durán (2011), “según la cual debe cautelarse la vigencia de la norma ante la mera afirmación del delincuente -con su hechode que "la norma no rige", aparece como justificadora del castigo y no limitadora del ius puniendi". (Durán, 2011, p. 141)

En efecto, la segunda dificultad revelada por Schünemann (2008), citado por Durán (2011) consiste en que la teoría absoluta, dentro del marco de la filosofía de la libertad fundada por Kant, presupone la libertad: de voluntad del autor del delito a retribuir. Por consiguiente, la diferencia entre el hombre como parte del mundo de los sentidos: "sujeto empírico" y del hombre como yo inteligible: "sujeto trascendental" forma la base fundamental del derecho y de la moral. Por tanto, conforma también la base de la teoría absoluta de la pena, como algo no tomado de la experiencia, sino surgido de un modelo de pensamiento de la razón pura. 
Así, "es como el hombre se puede liberar de los impulsos de la sensualidad y, en virtud de su comprensión, obrar conforme a los deberes morales que resultan del imperativo categórico" (Durán, 2011, p. 142). En síntesis, entender el yo inteligible como la libertad de motivarse hacia lo bueno o hacia lo malo, sin que Kant haya desarrollado para ello en los estudios sobre religión o antes en sus escritos críticos una concepción total, se trataría de una simple suposición ad-hoc que no puede hacer plausible justamente la libertad y, con ello, la imputación del delito.

Finalmente, tampoco la moderna fundamentación de la pena de la "filosofía de la libertad" ha tratado esa aporía, ni mucho menos la ha eliminado. No obstante, quedan todavía tres soluciones: o nos atenemos a una concepción hoy extendida del concepto social de culpabilidad, que no requiere más una prueba de la libertad del autor, sino solo de su promediabilidad, o renunciamos por completo a un concepto de culpabilidad derivado del pensamiento de la libertad y lo reducimos a la prevención general, tal como lo había propuesto Jakobs antes de su cambio radical de Luhmann a Hegel. Y con ello cedemos también una legitimación del derecho penal establecida al margen de la utilidad y aceptamos, además, el surgimiento de las contradicciones entre una teoría de la pena sustentada originalmente de manera prevención general y otra teoría de la pena sustentada ahora sobre Hegel, esto es, sobre una filosofía de la libertad, no fundamentada por sí misma de manera lo suficientemente plausible. En definitiva, se promueve, una nueva prueba de la libertad de la voluntad independiente de Kant o, dicho más precisamente, del concepto necesario de libertad para la fundamentación de la culpabilidad penal. (Durán, 2011)

\section{Las diferencias fundamentales entre las teorías del derecho penal y la pena}

Hasta aquí, se ha tomado en consideración sólo el estudio de las tres teorías con sus respectivas subdivisiones sobre los fundamentos del derecho penal y la pena. Ahora, resulta necesario pegar una mirada resumida a las diferencias fundamentales entre las diversas teorías del fundamento del derecho penal y la pena. Las teorías absolutas observan hacia el pasado, es decir, ¿qué fue lo que pasó? [Un delito] para con fundamento en su existencia, retribuir con un castigo.

Dicho de otra manera, para esta tendencia, la pena está legitimada en la existencia del delito, y hacer justicia significa la motivación de la pena sin importar la finalidad de la misma. Pues, admiten a la pena como un fin en sí mismo, es decir como castigo, compensación, reparación y retribución. Lo que 
en la realidad concierne es saber: ¿cuándo se castiga?, no ¿para qué se castiga? Tampoco es importante para esta concepción saber ¿por qué se prohíbe?

Por tanto, existe una legitimación externa de la pena que está dada en la existencia misma del delito. Esto sólo es posible a través de la teoría absoluta en su tendencia retributiva, pues en ella encontramos la limitación absoluta de la pena definida relativamente o del respaldo concerniente de una justificación, como queda dicho. En cambio, las teorías relativas con sus tendencias de la prevención observan el futuro, es decir, ¿qué justifica la existencia de la pena? [Un prevenir]. Por cierto, que la validez de la pena está dada por su utilidad.

Estas teorías también han sido denominadas como "utilitaristas" al percibirlas como la vía indispensable para la realización de un fin: la prevención de futuros delitos respecto al colectivo de individuos, si hablamos de una prevención general positiva o negativa y frente a la persona del sujeto activo del delito, si nos referimos a una prevención especial. La teoría relativa de la prevención general nos absuelve el interrogante ¿por qué se prohíbe y para qué se castiga? En concreto, de igual manera nos justifica la imposición de una pena señalando una justificación interna, en otras palabras, se establece la razón de la pena con fundamento a lograr una finalidad, que es eminentemente, de carácter preventivo. Planteada la cuestión en dichos términos, -como dice Bacigalupo (1999)-:

No debe deducirse que los motivos de prevención especial deban quedar fuera de consideración en la medida de la pena, y mucho menos que deba ceder a razones impuestas por la prevención general. Agrega el autor-: (...) de lo que se trata es de determinar qué límite debe reconocerse a las razones preventivo- especiales en la medida de la pena. (pp. 263-264)

Es evidente, entonces, en nuestra opinión, que esta teoría de la prevención general negativa basada en la pena ejemplar tiene el mérito de no confundir el derecho con la moral o la naturaleza.

Las teorías mixtas o de la unión son producto de las combinaciones de las ideas fundamentales de las teorías absolutas y relativas de la pena. En primer lugar, se combinaron las teorías de la retribución con las de la prevención tratando de relacionar las partes negativas de cada una de ellas. Inmediatamente, ante las críticas demostradas al tratar de unir dos concepciones absolutamente disímiles como: retribución-prevención, centralizan su atención en descubrir técnicas o métodos que admitan el entendimiento entre la prevención general y la especial. 
Por último, se puede afirmar que llegaron a reflexionar que el inconveniente medular del derecho penal no es en realidad penar, sino su eventual selección de los llamados bienes jurídicos protegidos (humanos y sociales). En cambio, otros se inclinan por la formulación de un "derecho penal mínimo" y, además, hay quienes se inclinan por las posiciones abolicionistas. En definitiva, a nuestro juicio esta discusión, sin duda, producirá un mejoramiento, que permita tratar al delincuente condenado como ser humano. Pues, de ser así, he de ver lo que tantos grandes hombres y mujeres, no sólo que han escrito, sino que han promovido, por nuestra parte, anhelamos que así sea.

Dentro de estas tendencias mixtas observamos la "teoría dialéctica de la unión" formulada por Roxin (1997), en la que se distingue tres fases. La primera, llamada de comunicación o amenaza, en la que la pena cumple un fin de prevención general, y su función es proteger los llamados bienes jurídicos. La segunda, de la aplicación o determinación de la pena, precisamente, es en esta fase donde se confirma la amenaza del Estado. Y la última circunstancia, que consiste en la ejecución de la pena, aquí se ven ratificados los fines y objetivos ulteriores de la pena, pero encausados en la utopía de la resocialización del reo condenado.

Es irrebatible, a la sazón, que dicha resocialización -como sabiamente afirma Welzel (1969) - "no es suficiente para aclarar el sentido de la pena, como un mal merecido por la violación culpable del derecho, cuando la ejecución del mal hace al condenarlo peor de lo era" (p.263).

Por nuestra parte, no debemos hablar de resocialización del condenado, sino de la [sociedad], ya que la resocialización "es entendida no como una reinserción del interno a una sociedad que lo rechaza o que aquel no acepta, sino como modesta posibilidad de ser capaz de llevar una vida de libertad sin delito" (García Valdez, 1995, p. 9). Asimismo, debe ser entendida como el "proceso de reaprendizaje de las expectativas sociales de los roles que motivan la conducta, y esta debe darse en espacios funcionales que permitan el entrenamiento de la integración permanente a la sociedad" (Acosta, 1996, p. 147). Así, también la noción resocialización consiste en "recuperar para la sociedad, por consiguiente, restablecer en el delincuente el respeto por las normas básicas, evitando así la comisión de nuevos delitos, en una palabra, la reincidencia”. (Chimeri, 1994)

Sobre dichos sentidos Baratta (1990) nos plantea -por encima de la resocialización- la idea de la reintegración a la sociedad no debe abandonarse, puesto que implica un proceso de comunicación e 
interacción entre la prisión (cárcel) y la sociedad, en el que los ciudadanos y ciudadanas recluidos en la prisión (cárcel) "se reconozcan" en la sociedad externa y la sociedad externa "se reconozca" en la prisión, aun cuando sentencia que este no debe intentar conseguirse a través de la prisión, sino a pesar de ella. Además, Baratta (1990) nos enseña de que no se trata solo de mejor prisión (cárcel) sino también menos prisiones (cárceles) - como opción efectiva-para lograr sanciones o penas alternativas.

Como la resocialización constituye un paradigma de los ordenamientos jurídicos penales modernos, en opinión de Muñoz Conde (1982) "hablar de resocialización del delincuente sólo tiene sentido cuando la sociedad en la que va a integrarse el delincuente tiene un orden social y jurídico que se estime correcto" (p. 390). Por ello, compartiendo con el autor consideramos también que en ocasiones es la sociedad la que debiera resocializarse y no el delincuente. Sin embargo, la dimensión crítica de estas teorías mixtas o de la unión presupone un modelo ideal de sociedad con el que se compara la sociedad cuyo aparato de control social se critica. Por consiguiente, son éstas las teorías más acogidas actualmente en la doctrina jurídico penal, puesto que, toda dogmática penal parte de una determinada idea de la legitimidad del ejercicio del poder punitivo del Estado y para ejercerlo, obviamente, necesita encontrar en sus fundamentos teóricos el punto de partida para el correcto entendimiento y determinar el contenido y los límites tanto del poder como de la pena.

Como corolario el tema sobre las teorías que fundamentan la pena [absolutas: retribución; y, teológica (retribución de la pena y retribución moral de la pena) y relativas: pacto social, utilitaria, defensa social y mixtas o de la unión] y las diferencias entre las teorías del derecho penal y la pena, tratados por ordenadamente en líneas anteriores, ofrece además perspectivas interesantísimas que exceden del ámbito de este trabajo, desde el finalismo ortodoxo de Welzel [padre del finalismo, durante los años treinta y comienzo de los años cuarenta del siglo XX] en la conocida como la teoría de la acción final, en la que reúne la voluntad en forma integral en la conducta humana; misma que se da en dos fases [interna y externa].

Los seguidores de Welzel [Maurach, von Weber, Busch y Niese] entienden que la conciencia de la antijuricidad (relevancia jurídica de la acción) no es uno de los elementos del dolo, sino que se sitúa en la culpabilidad (teoría de la culpabilidad) como elemento independiente. Para Maurach (1962) no implica que la cuestión del conocimiento del injusto dentro del dolo, sino dentro de la culpabilidad. Tampoco debe exigirse la presencia positiva, actual del conocimiento del injusto, sino que nos 
contentamos con el llamado conocimiento potencial del injusto; el autor ya ha obrado de modo culpable tan solo si tenía la posibilidad de conocer la antijuricidad de un hecho, y no importa si la conoció en la realidad. En síntesis, los seguidores de Welzel, han contribuido a acentuar la posición subjetiva, e incluso en lo injusto, dando lugar al surgimiento de la sistemática finalista, a la cual en el Ecuador seguiría el profesor Jorge Zavala Baquerizo, desde la concepción finalista [más liberal] del profesor alemán Reinhart Maurach.

\section{La suspensión condicional de la pena}

Como se sabe de manera general la suspensión condicional de la pena, es un beneficio penitenciario consistente en la cesación de la ejecución de la pena de privativa de libertad, en los delitos cuya duración de la pena impuesta al justiciable no exceda de cinco años, con la excepción de los delitos sexuales y los de violencia intrafamiliar, como veremos a continuación.

\section{Regulación de la suspensión condicional de la pena}

Los presupuestos de su procedencia están regulados en el Código Orgánico Integral Penal y establece:

La ejecución de la pena privativa de libertad impuesta en sentencia de primera instancia, se podrá suspender a petición de parte en la misma audiencia de juicio o dentro de las veinticuatro horas posteriores, siempre que concurran los siguientes requisitos:

Que la pena privativa de la libertad prevista para la conducta no exceda de cinco años.

Que la persona sentenciada no tenga vigente otra sentencia o proceso en curso ni haya sido beneficiada por una salida alternativa en otra causa.

Que los antecedentes personales, sociales y familiares del sentenciado, así como la modalidad y gravedad de la conducta sean indicativos de que no existe necesidad de la ejecución de la pena.

No procederá en los casos de delitos contra la integridad sexual y reproductiva, violencia contra la mujer o miembros del núcleo familiar.

La o el juzgador señalará día y hora para una audiencia con intervención de la o el fiscal, el sentenciado, la o el defensor público o privado y la víctima de ser el caso, en la cual se establecerán 
las condiciones y forma de cumplimiento durante el período que dure la suspensión condicional de la pena. (art. 630)

El juzgador -singular o plural- de la sentencia de primera instancia es quien debe motivar la suspensión condicional de la pena, de acuerdo a las circunstancias personales del condenado, las del hecho y la duración de la pena, exigiéndose -entre otras condiciones- la reparación integral de los daños causados a la víctima.

\section{Control de la suspensión condicional de la pena}

El COIP, establece la obligación del juzgador para realizar el debido control del justiciable favorecido con la suspensión condicional de la pena. Así, muy bien, puede notarse:

La o el juzgador de garantías penitenciarias será el encargado del control del cumplimiento de las condiciones. Cuando la persona sentenciada incumpla cualquiera de las condiciones impuestas o transgreda el plazo pactado, la o el juzgador de garantías penitenciarias ordenará inmediatamente la ejecución de la pena privativa de libertad. (art. 632)

\section{Extinción de la suspensión condicional de la pena}

El COIP, instituye la extinción de la pena privativa de libertad, cuando dice: "Una vez que la persona sentenciada haya cumplido con las condiciones y plazos establecidos en la suspensión condicional de la pena, la condena quedará extinguida, previa resolución de la o el juzgador de Garantías Penitenciarias”. (art. 633)

Como puede notarse, la impronta más interesante sobre el proceso de evolución del sistema penal hoy en día, es la previsión de los mecanismos tendentes a evitar la aplicación de las penas privativas de libertad que no resultan -absolutamente- necesarias. Finalmente, como consecuencia de la sucesiva humanización de las normas jurídico penales, las penas privativas de libertad -en la actualidadresultan excesivas en muchas ocasiones. Por ello, el COIP -como lo hemos dejado plenamente establecido- en sus artículos 630-633, fija la regulación, control y extinción sobre la suspensión condicional de la pena y las condiciones que debe de cumplir el justiciable sentenciado durante el período de duración de la suspensión de la pena. 


\section{La medida de seguridad}

La teoría de la medida de seguridad fue formulada por primera vez por Klein, citado por Aróstegui (2011) en la que establecía de forma novedosa y por primera vez, una diferencia entre la medida de seguridad y la pena.

En síntesis, la diferencia consistía en el hecho que la medida de seguridad no contenía un sentido aflictivo como lo tiene la pena, y atendía, más a la peligrosidad del sujeto que a la culpabilidad. La duración de esta medida era indeterminada y el control de la aplicación correspondía al juez o jueza.

De lo expuesto se colige que, la medida de seguridad, está a la mira de la peligrosidad del individuo que delinque. Esta es una medida de prevención especial, y podrán ser determinadas sobre la base de los antecedentes del justiciable [imputable y/o inimputable] y su finalidad es prevenir a la sociedad de ataques futuros.

\section{Medida de seguridad}

La medida de seguridad es un especial tratamiento impuesto por el Estado a determinados delincuentes encaminados a obtener su adaptación a la vida social [medida de educación, de corrección, y de curación], o su segregación de la misma [medida en estricto sentido] (Cuello, 1975).

Como se sabe, en el contexto del derecho penal, la medida de seguridad, son aquéllas sanciones complementarias o sustitutivas de las penas que el juez o jueza puede imponer con efectos preventivos al sujeto que comete un injusto penal. Por lo tanto, de acuerdo con la teoría del delito el sujeto inimputable no puede ser declarado culpable. Así, esta persona es susceptible de recibir una medida de seguridad para evitar que en su condición de "inimputable" vuelva a cometer nuevos injustos penales.

\section{Objetivo de las medidas de Seguridad}

La medida de seguridad tiene como objetivo principal la prevención de futuros delitos, que pudieran ser cometidos por el infractor del ordenamiento jurídico-penal, considerando principalmente la peligrosidad del sujeto y se concretan con corrección, socialización, tratamiento y educación sobre el individuo considerado como peligroso. 


\section{La medida de seguridad en la legislación ecuatoriana:}

\section{La medida de seguridad en el contexto constitucional}

La vigente Constitución (2008) reconoce como uno de los principios y derechos fundamentales el de la igualdad, y sostiene que "todas las personas son iguales y gozaran de los mismos derechos, deberes y oportunidades" (núm. 2, art. 11). Dispone, asimismo:

Nadie podrá ser discriminado por razones de etnia, lugar de nacimiento, edad, sexo, identidad de género, identidad cultural, estado civil, idioma, religión, ideología, filiación política, pasado judicial, condición socio-económica, condición migratoria, orientación sexual, estado de salud, portar VIH, discapacidad, diferencia física; ni por cualquier otra distinción, personal o colectiva, temporal o permanente, que tenga por objeto o resultado menoscabar o anular el reconocimiento, goce o ejercicio de los derechos. La ley sancionará toda forma de discriminación. (num. 2, art. 11)

Frente a situaciones reales de desigualdad y para garantizar el derecho a la igualdad -como política pública- "el Estado adoptará medidas de acción afirmativa que promuevan la igualdad real en favor de los titulares de derechos que se encuentren en situación de desigualdad". (art. 11, num. 2 de la Constitución)

Dentro de esta perspectiva, la Constitución en el num. 4 del art. 66, reconoce el derecho a la igualdad formal y material y la no discriminación. Por ello, nuestra Carta Fundamental autoriza a favor de todas y cada una de las personas incapaces o disminuidas psíquicamente un trato diferente y preferencial, y como lo dice la Corte Constitucional del Ecuador:

(...) se dice que el principio de igualdad y no discriminación no puede ser analizado de una forma general, porque existen particularidades en las cuales se radican diferencias entre uno y otro individuo, que harían pensar que el tratamiento no es igualitario, cuando no es esa la realidad. Se reitera diciendo que este principio opera cuando las personas se encuentran en idénticas condiciones. (Sentencia No. 007-10-SIN-CC) 


\section{La medida de seguridad en el derecho penal ecuatoriano}

La legislación positiva ecuatoriana ha definido a la medida de seguridad como pena no privativa de libertad: tratamiento médico, psicológico, capacitación, programa o curso educativo (COIP, art. 60 núm. 1). En síntesis, este tipo de pena es una limitación del derecho a la libertad, producto de la especial condición propia de una persona que atacó un bien jurídico tutelado.

Sin embargo, se podría afirmar, que la medida de seguridad debe tener un tiempo límite de duración. Se aplica medida de seguridad a personas imputables. Por ejemplo, en el primer inciso del art. 36 del COIP se establece que no será penalmente responsable quien, en el momento en que se realizó la acción u omisión, no tuvo la capacidad de comprender la ilicitud de su conducta o de determinarse de conformidad con esta comprensión, en razón del padecimiento de un trastorno mental. En estos casos el juez o jueza debe dictar una medida de seguridad. En el segundo inciso del art. 36 del COIP también determina para la persona que, al momento de cometer el acto delictivo, se encuentra disminuida en su capacidad de comprender la ilicitud de su conducta o de determinarse de conformidad con esta comprensión, tendrá responsabilidad atenuada. Asimismo, en el art. 76 del COIP se establece que: el internamiento en un hospital psiquiátrico, como medida de seguridad aplicable a la persona inimputable por trastorno mental. Esta medida tiene una finalidad tentativa que consiste en lograr la superación de la perturbación y la inclusión social del inimputable. Ciertamente, es impuesta por las o los juzgadores, previo informe psiquiátrico, psicológico y social, que acredite su necesidad y duración.

Como se ha expuesto, en la actualidad, la medida de seguridad puede ser impuesta a individuos tanto imputables como inimputables, como pena principal, accesoria o sustitutiva, es decir, que el juez o jueza puede imponer en sentencia una pena y una medida de seguridad al mismo tiempo.

\section{Diferencias entre pena y medida de seguridad}

La pena se diferencia de las medida de seguridad, a nuestro criterio y siguiendo al profesor Zavala (1986a) por las siguientes razones: a) es un juicio de reproche; b) su fin es la restauración del orden jurídico; c) inclina su mirada al delito cometido y al daño producido; d) persigue la intimidación; e) su función es la retribución; f) persigue una prevención general; g) es determinada en su duración; h) sólo puede ser aplicada por autoridad jurisdiccional competente; i) contra ella procede recurso; j) puede ser aplicada exclusivamente a imputables; $\mathrm{y}, \mathrm{k}$ ) sólo puede aplicarse posterior al cometimiento 
del delito. La medida de seguridad se diferencian de la pena, consideramos que y siguiendo la orientación de Zavala (1986a) por las siguientes razones: a) no hay reproche moral; b) tienden a la protección de la sociedad; c) inclinan su mirada a la peligrosidad del sujeto; d) no persiguen la intimidación; e) la función es la prevención especial; f) no persiguen una prevención general; g) son indeterminadas, durarán hasta cuando persigan el estado de peligrosidad del sujeto; h) pueden ser aplicadas por diversas autoridades; i) por lo general no proceden recursos en contra de ellas; j) pueden ser aplicadas a inimputables y/o a inimputables; $y, k$ ) sólo pueden aplicarse ante el cometimiento del delito.

\section{Metodología}

La metodología utilizada fue de tipo descriptivo documental bajo un enfoque cualitativo. El corpus de la investigación estuvo constituido por la revisión bibliográfica y documental de los estamentos legales y teóricos de la pena jurídica ecuatoriana y de las improntas del itinerario jurídico del ilustre maestro Jorge Zavala Baquerizo sobre la teoría de la pena. Los resultados se fundamentaron en el origen, justificación y naturaleza de la pena, desde el paradigma del principio de legalidad reglado en el numeral 3 del artículo 76 de la Constitución de la República del Ecuador.

\section{Conclusiones}

Durán (2011) anuncia que la crítica hecha a la llamada prevención general positiva y al fracaso del ideal resocializador, es necesario pasarle una mirada a las teorías absolutas o retributivas de la pena, con el fin de volver a evaluar sus posibilidades de aplicación. Esta idea, abre la puerta a la posibilidad de hacer las valoraciones actuales a la luz del respeto irrestricto de los derechos fundamentales, es decir, poniendo límites materiales al ius puniendi, desde el contexto del Estado constitucional de derechos y justicia. Dejar lo que se sigue planteando como tradicionalmente se ha hecho, es decir, "de manera absoluta, represiva y solo orientada al restablecimiento del orden jurídico y a la realización de la justicia, se constituye como una teoría ajena a las necesidades del mundo actual y negadora de la condición actual del hombre”. (Durán, 2011, pp. 142-143)

Por ello es tan importante enmarcarla con base a consideraciones científicas, puesto que, al no hallar nuevos elementos sino más de lo mismo, pero con otra locución y conceptos, "el neo-retribucionismo 
La pena desde la axiología jurídica, a partir del itinerario jurídico de Jorge Zavala Baquerizo

vuelve a imponer intencionalmente la idea de la pena como un mal, sin justificar si este mal favorece a alguien; al condenado, a la sociedad o a la víctima”. (Durán, 2011, p. 143)

Es necesario -en la actualidad- fortalecer y apoyar la investigación científica, el análisis o revisión objetiva de las teorías retributivas de la pena, bajo rigor académico, partiendo de las improntas de las tendencias neo-retribucionistas, en tanto que el no hacerlo, estas como heredero directo de las teorías absolutas de la pena, al basarse en conceptos y categorías tales como "negación de la injusticia", "restitución de la justicia violada" y no en interés social del hombre, es una teoría arrogante y puramente de papel. (Hassemer y Muñoz Conde, 1989, p. 150; citado por Durán, 2011, p. 143)

\section{Referencias Bibliografícas}

Bacigalupo, Enrique (1999). Derecho penal. Parte general. (2 ${ }^{\mathrm{a}}$ ed.). Buenos Aires: Ed. Hammurabi. Baratta, Alessandro. (1990). Resocialización o Control Social. Por un concepto crítico de "reintegración social" del condenado. Ponencia presentada en el Seminario "Criminología Crítica y Sistema Penal”, organizado por Comisión Andina Juristas y la Comisión Episcopal de Acción Social, en Lima, del 17 al 21 de septiembre de 1990. Traducción de Mauricio Martínez. Universidad de Saarlan R.F.A. Disponible en:https://es.scribd.com/document/80416092/BARATTA-AlessandroResocialización-o-Control-Social [Consulta: 06-11-2016]

Bentham, Jeremías (1938). Teoría de las penas y las recompensas. Traducida al español de la tercera edición publicada en Francia por D.L.B. Barcelona: Ed. Imprenta de Manuel Sauri. Binding, Karl (1927). Compendio di diritto penale (trad. Adelmo Borettini). Roma. Bobbio, Norberto (2001). "No matarás". Península. En Argumentos de ocho intelectuales contra la pena de muerte. Avance (publicado en La Vanguardia, 26-8-01). Recuperado en: http://www.amnistiacatalunya.org/edu/2/pm/pm-cites-norberto-bobbio.html. [Consulta: 06-11-2016] Bramont-Arias Torres, Luís Miguel (2000). Manual de derecho penal. Parte general. Lima: Ed. Santa Rosa.

Chimeri Sorrentino, Rodolfo. "La resocialización del delincuente. Asignatura pendiente”. En Gaceta del Foro. Diciembre de 1994.

Cobo del Rosal, Manuel \& Vives Anton, Tomás (1990). Derecho penal. Parte general (3º ed.). Valencia: Ed. Tirant lo blanch.

Cuello Calón, Eugenio (1960). Derecho penal. Barcelona: Bosch Casa Editorial S.A. Cuello Calón, Eugenio (1975). Derecho penal. Parte general. Barcelona: Bosch, Casa Editorial S. A. 
Durán Migliardi, Mario (2011). "Teorías absolutas de la pena: origen y fundamentos Conceptos y críticas fundamentales a la teoría de la retribución moral de Immanuel Kant a propósito del neoretribucionismo y del neoproporcionalismo en el Derecho penal actual". En Revista de Filosofía. Vol. 67. (pp. 123-144)

Feijoo Sánchez, Bernardo. (2007) "Individualización de la pena y teoría de la pena proporcional al hecho. El debate europeo sobre los modelos de determinación de la pena", en INDRET. Revista para el análisis del Derecho. 1/2007.

García Valdez, Carlos (1995). Comentarios a la legislación penitenciaria. Madrid: Ed. Civitas Ediciones.

Grispigni, Filippo (1948). Derecho penal italiano (2 $2^{\mathrm{a}}$ ed.). (Vol. 1-1). Isidro de Benedetti (ed). Buenos Aires: Ed. Depalma.

Hassemer, Winfried-Muñoz Conde, Francisco (1989), Introducción a la criminología y al derecho penal. Valencia: Ed. Tirant lo Blanch.

Hegel, Georg Wilhelm Friedrich (1968). Filosofía del derecho. (5ª ed.). Angélica Mendoza de Montero (trad.), quien la ha tomado de la versión italiana de Francisco Messineo, publicada bajo la dirección de Benedetto Croce y G. Gentile. Buenos Aires: Ed. Claridad S.A.

Hegel, Georg Wilhelm Friedrich (1986a). Grundlinien der Philosophie des Rechts. (1 $1^{\mathrm{a}}$ ed.). Frankfurt Del Meno: Ed. Suhrkamp.

Hegel, Georg Wilhelm Friedrich (1986b). Phänomenologie des Geistes. (1 $1^{a}$ ed.) Frankfurt del Meno: Ed. Suhrkamp.

Kant, Immanuel (1989). La metafísica de las costumbres. Estudio preliminar de Adela Cortina Orts. Trad. y notas de Adela Cortina Orts y Jesús Canal Sancho. Madrid: Tecnos. Título original Metaphysik der Sitten (1797).

Kant, Immanuel (2005). La metafísica de las costumbres (trad. Adela Cortina Ortiz \&Jesús Conill Sancho). $4^{\text {a }}$. ed. Madrid: Ed. Tecnos.

Labatut Glena, Gustavo (1979). Derecho penal. $8^{\text {a }}$. ed. (Vol. 1). Santiago, Chile: Ed. Jurídica de Chile. Marí, Enrique Eduardo (1983). La problemática del castigo. Buenos Aires: Ed. Hachette.

Maurach, Reinhart (1962). Tratado de derecho penal. Juan Córdoba Roda (trad. y notas de derecho español). Barcelona: Ed. Ariel.

Muñoz Conde, Francisco \& García Arán, Mercedes (2007). Derecho penal. Parte general. Valencia: Ed. Tirant lo Blanch. 
Muñoz Conde, Francisco (1977). Introducción al derecho penal. Barcelona. Ed. Bosch Casa Editorial S. A.

Roxin, Claus (1997). Política criminal y sistema del derecho penal (trad. Francisco Muñoz Conde). Barcelona: Bosch Casa Editorial S.A.

Schünemann, Bernd (2008). "Aporías de la teoría de la pena en la filosofía. Pensamientos sobre Immanuel Kant", INDRET Revista para el análisis del derecho.

Vidaurri, Aréchiga, Manuel (1999). “Concepto contenido y función del derecho penal”. En: Revista de Investigaciones Jurídicas. Universidad de Guanajuato, No. 67. México.

Vidaurri, Aréchiga, Manuel (2012) Introducción al derecho penal. Colección de Textos Jurídicos Universitarios, Oxford, University Press, S.A de C.V.

Villa Stein, Javier (1998). Derecho penal. Parte general. Lima: Ed. San Marcos.

Welzel, Hans (1956). Derecho penal. Parte general. Buenos Aires: Roque de Palma (ed).

Welzel, Hans (1965). El nuevo sistema de derecho penal (una introducción a la doctrina de la acción finalista). Barcelona: Ed. Ariel.

Welzel, Hans (1987). Derecho penal alemán. Parte general (12 ed.). ( $3^{\mathrm{a}}$ ed. Castellana, trad. Juan Bustos Ramírez \& Sergio Yáñez Pérez). Santiago: Editorial Jurídica de Chile, Chile.

Zaffaroni, Eugenio Raúl, Alagia, Alejandro \& Slokar, Alejandro (2000). Derecho penal. Parte general ( $1^{\mathrm{a}}$ ed.). Buenos Aires: Ed. Ediar.

Zambrano Pasquel, Alfonso (1998). Manual de derecho penal (2 ed.). Guayaquil: Ed. Edino. Zavala Baquerizo, Jorge (1986a). La pena en general (1 ${ }^{\mathrm{a}}$ ed.). (Vol. 1). Guayaquil: Ed. E.Q. 